RESEARCH ARTICLE

\title{
Ecological Role of the Insect Pollinators in Seed Yield of Cross Pollinated Sesamum indicum from West Bengal, India
}

\author{
Biswanath Bhowmik, Udipta Chakraborti, \\ Kakali Bhadra* \\ Department of Zoology, University of Kalyani, Kalyani, West \\ Bengal, Pin- 741235, India \\ Study Area: Hijli, Kamarpur \& Nurpur of Villages \\ of North 24 paraganas, West Bengal, india \\ Coordinates: $22^{\circ} 83^{\prime} \mathrm{N}$; $88^{\circ} 69^{\prime} \mathrm{E}, 2^{\circ} 83^{\prime} \mathrm{N}$; 88 ${ }^{\circ} 5^{\prime} \mathrm{E}$ \\ $\& 22^{\circ} 90^{\prime} \mathrm{N}$ and $88^{\circ} 57^{\prime} \mathrm{E}$
}

Key words: Apis (Megapis) dorsata, Apis mellifera

Abbreviation used: VR- Visitation Rate; HR- Handling Time

\section{Abstract}

To explore the insect flower visitors of Sesamum indicum L. and their role in seed yield a study was conducted during the year 2014 to 2016 in South Bengal regions. The yield of crosspollinated plants was significantly higher with respect to seed width, length, and diameter than self-pollinated plants. A total number of 15 insect species under orders Diptera, Hymenoptera and Lepidoptera were recorded from 6:00 am to 6:00 pm survey. Though the dipteran insects were more diversified, the most abundant insect species were Apis (Megapis) dorsata (20.71\%) and Apis mellifera $(17.57 \%)$ respectively, from the order Hymenoptera. Among them, A.dorsata was included with a strong linear relationship with bloomed flower and showed higher visitation rate and handling time than A.mellifera. Furthermore, A.dorsata showed higher value of pollination efficiency index than A.Mellifera. Total $77 \%$ pollens were found to be viable from the anther lobe of flower whereas A. dorsata was carrying $73 \%$ of viable pollen. Therefore, Apis (Megapis) dorsata may be the most efficient pollinator and played an important role in higher seed yield in S.indicum.

benefited from faunal pollination, whereas wind and selfpollination are sufficient for only about $28 \%$ crop species (Klein et al., 2007). Animal-mediated pollination contributes to the sexual production of over $90 \%$ species of modern angiosperms and among them, insects are the main responsible factors (Saini et al., 2012). Co-evolution of flowering plants and their pollinators started about 225 million years ago (Price, 1975). Effective pollination results in increased crop production, quality improvement, and more seed production. Many fruits, vegetables, edible oil crops, and nuts are highly dependent on bee pollination (Irshad \& Stephen 2014). The present investigation focuses on the foraging activity of different insect fauna and their abundance on Sesamum flowers with special reference to the abundance and role of the active pollinators in increasing the seed yield in the self and cross-pollinated crop both qualitatively and quantitatively thereby increasing the germinability of the resulting seeds of Sesamum sp. The work further highlights the pollination eff iciency and ecological services played by the pollinators. The study was conducted for the first time from the unexplored area of North 24 Parganas of West Bengal, India. 


\section{Methodology:}

Study area: the study was conducted with the concern of agricultural field of S.indicum (Variety: Tillittoma B67) plant at Hijli Village, Kamarpur Village and Nurpur Village of district North 24 Paraganas in the state of West Bengal, India during the year 2014 to 2016 . The work was processed during the flowering time of the plant e.g. March to end of May. Average temperature and average humidity of this region during the surveywere $29^{\circ} \mathrm{C}$ and $64 \%$ respectively.

Tragetted plant: Sesamum sp. is a herbaceous annual plant, growing to a height of 1.0-2.0 $\mathrm{m}$. The taproot bears only a few secondary and tertiary roots. The stem is erect, normally square in section. The upper part of the stem is particularly covered with short hair. Some varieties have profuse branching and give the plant a bushy appearance. The leaves are alternate and opposite. The leaf size may vary from 3.0 to $17.0 \mathrm{~cm}$ in length and 1.0 to $7.0 \mathrm{~cm}$ in width. The inflorescence is a receme and the fruit is a capsule. Though like other oilseed crops the flower structure of Sesamum facilitates cross-pollination, but it is also considered to be self-pollinated. Hence this study was focused on the comparative study of seed yield in self-pollinated and crosspollinated plant. Different orders from insect group have been reported to forage on Sesamum flower (Mahmoud, 2012). Besides honeybees, other pollinators such as flies, butterflies, and wasps were recorded on the flowers in open pollination (Desai, 2004).

Sampling: a total of 10 quadrates with the size of $1 \mathrm{~m} \times 1 \mathrm{~m}$ were selected randomly in the field for collection of data. On an average, 28 to 30 plants were present in each quadrate and half of the plants from each quadrate were bagged (Close) for monitoring self-pollination. The unbagged plants (Open) were the representative of cross-pollination system. Each quadrate was observed from 6 am to $6 \mathrm{pm}$ with the time intervals of 2 hours i.e. 6 am -8 am, 8 am -10 am, 10 am- -12 pm, 12 pm-2 pm, 2 pm - 4 pm and 4 pm -6 pm, thrice in a week.

Plant data collection: the seeds and fruits were collected from both bagged (Close) and unbagged (Open) plants. The seeds were measured with respect to length, diameter, and width. Bagging was done 14 hrs before the opening of the flowers. A total number of 100 seeds were weighed from both bagged and unbagged plants to observe the difference in total weight in both cases. To observe the plantlets growth from the seeds of open and close pollinated plants, seeds were planted and after germination, the length/ height of the saplings was measured.

Insect collection, preservation, identification, sampling technique, and data collection: insects, which were exclusively flower visitor of the targetted plant, were collected after taking the necessary data. If the insect specimen was identified on the field then photograph and necessary data from that specimen were taken without having it. If necessary, the insect collection was made by the help of round-headed insect net. The process of collection, preservation, setting, and pinning of the collected insects were followed from the manual of Zoological Survey of India (Jonathan \& Kulkarni, 1986). For further identification, the specimens were taken to the Zoological Survey of India, Kolkata.

The quadrats were monitored during the study period and only the individual numbers of flower-visiting insect species were tabulated. Selected individuals of each insect species were continuously followed while they were foraging on the flowers of S. indicum plants till the necessary data were collected. In each observation period, total time spent on flower (TF; from the time of touching to departure of the flower by the insect) and total observation time (TT; this observation was included with the time spend on flower and the time in flight between next flower) were accumulated with the help of separate stopwatches and total number of flower visited (NF) were also recorded. These data were helping us to analyze - a) VR (VR), in per unit of time average number of flowers visited [VR=NF/TT]; b) Handling time (HT), average time spent on each flower $[\mathrm{HT}=\mathrm{TF} / \mathrm{NF}]$ (Herrera, 1989; Meerabai, 2012). The insects were observed from $6 \mathrm{am}$. to $6 \mathrm{pm}$. with the time intervals of 2 hours i.e. $6 \mathrm{am}-8 \mathrm{am}$, $8 \mathrm{am}-10 a \mathrm{am}, 10 a \mathrm{~m}$ - 12pm, 12pm-2pm, 2pm-4pm and 4pm-6pm.

For Linear Regression Analysis, the plants were monitored with time duration of 3 minutes in the different time frame of the study period. The individual flowers visiting insect species number were recorded from each plant during the monitoring period. A total number of 50 plants were studied for this analysis.

Methods for pollination index and pollen germination test: pollination Index for the most abundant insect flower visitor was developed by following the process by Vithanahe (1990). This is a product of Flower and Insect visitor ratio in a unit of time (preferably an hour) and the number of studied plant pollen grains counted on the various body parts of insect visitor species.

The pollen germination test was performed artificially with help of different concentration of Sucrose solutions. The pollens were collected from an anther of this plant (just after anther dehiscence) and the body part of Apis (Megapis) dorsata. The process of pollen viability testing was performed by following the methodology by Bhowmik \& Bhadra (2015).

Ecological and statistical analysis: species diversity, dominance, and species richness were calculated by the help of Shannon Index (H'), Dominance Index (D) and Margalef Index respectively. These indices were performed by using the statistical software PAST 2017 (Version 3.17). To study the evenness, the Evenness Index (J') was calculated with the help of Biodiversity pro Version 2 software. Two tailed t-tests were conducted to compare seed yields among 
the open and close pollination system. The analysis was tested at the $\mathrm{p}<0.05$ level of significance. One way ANOVA has also been done foryear wise variation analysis of VR and Handling Time among two honey bee species. The t-test analysis and One Way ANOVA analysis were performed by using the statistical software PAST 2017 (Version 3.17). The number of bloomed flower in each plant was compared with the number of A.dorsata and Apis mellifera visiting on each plant per unit of time, by using Linear Regression analysis. Mean was separated by the help of F - statistics. A coefficient of determination, R2, was used to verify the strength of linear association. The Regression categories are as follows: a) 0.6 to 1.00 is a very strong relationship. b) 0.3 to 0.59 is a strong relationship, c) 0.1 to 0.29 is very weak relationship and $\mathrm{d}$ ) if the value of $\mathrm{R}_{2}$ is zero (Nonlinear) that determines there is no relationship (Ali et.al., 2016). The linear regression analysis was done by using $\mathrm{R}$ studio software Version 1.1.383.

\section{Results :}

Comparative yield of open (unbagged) and close (bagged) pollination in Sesamum indicum: the present study on S. indicum demonstrates that, this plant has a total lifespan of 70 days, with the flowering season from seed timing from mid of March to end of May. The pre-flowering stage was 3 to 4 weeks and a flowering stage was almost 6 weeks. The pod setting stage was 6 to 8 weeks after showing and maturity stage was 8 to 10 weeks.

Table-1: Two tailed T- Test analysis among the plantlets, seed and fruits collected from the plants of bagged and unbagged plants. Level of significance $(\mathrm{p}<0.05)$

\begin{tabular}{llll}
\hline Parameter & T test value & df (Degree of Freedom) p value \\
\hline Plantlets length & -1.6021 & 18 & 0.11741 \\
Fruit length & -1.5893 & 18 & 0.12029 \\
Fruit diameter & -6.698 & 18 & $2.7174 \mathrm{E}-08$ \\
Seed length & -6.1379 & 48 & $1.78 \mathrm{E}-08$ \\
Seed Width & -4.0837 & 48 & $9.06 \mathrm{E}-05$ \\
\hline
\end{tabular}

Fruits were studied on the basis of their length and diameter for the estimation of better fruit generation from both the open and close pollinated plants. In the case of open pollination and close pollination, the average fruit length was $25.22 \pm 0.31 \mathrm{~mm}$ and $24.41 \pm 0.40 \mathrm{~mm}$ respectively, and the average size of fruit diameters was $37.72 \pm 0.44 \mathrm{~mm}$ and $32.25 \pm 0.54 \mathrm{~mm}$ respectively. Seeds were also evaluated from the open and close pollinated plant samples on the basis of their length and diameter, where the average length of seeds from open-pollinated plant and close pollinated plant were $3.648 \pm 0.05 \mathrm{~mm}$ and $3.124 \pm 0.06 \mathrm{~mm}$ respectively. Average seed diameter was also measured for both the conditions where for open-pollinated plants the seeds were 2.2 $\pm 0.07 \mathrm{~mm}$ and for a close pollinated plant the seeds were $1.8 \pm 0.06 \mathrm{~mm}$. The average lengths of the plantlets from the seeds of both open and close pollinated plants were $14.85 \pm 0.76 \mathrm{~mm}$ and $13.35 \pm 0.53 \mathrm{~mm}$ respectively (Table-1). Seed weight measurement from these two pollination procedures showed higher seed weight in open pollination ( $\sim 0.74 \mathrm{~g})$ than the other one ( $\sim 0.27 \mathrm{~g})$.

Diversity of insect flower visitor of $\boldsymbol{S}$. indicum: as a cross-pollinating agent, insects played a crucial role in this case. A total number of 15 insect species reported as flower visitors, belonging to three major orders viz. Hymenoptera, Diptera, and Lepidoptera. Among them 8 species under 8 genera were reported from order Diptera, 6 species under 2 genera from order Hymenoptera and 3 species from 3 genera were from order Lepidoptera (Table-2, Fig.-1). Shannon-Weiner Index (H'), Dominance Index (D), Margalef Index and Evenness Index (J') were performed to analyze species diversity, dominance, species richness, and species evenness respectively, among the three orders. Order Diptera was included with the highest species diversity and species richness, followed by order Hymenoptera and Lepidoptera respectively. Order Lepidoptera was the dominant order with the lowest evenness among these three orders. The highest evenness showed by the order Diptera with the lowest dominance (Fig.-2). The relative abundance ranking graph demonstrated that among the 15 insect flower visitors, most abundant species was A.dorsata and A.mellifera respectively. The least abundant flower visitor was the lepidopteran species Danaus plexippus.

Table-2: List of insects flower visitors of Sesamum indicum plant and their Relative abundance (RA)

\begin{tabular}{|c|c|c|c|}
\hline Species name & RA $(\%$ & Species name & $\mathrm{RA}(\%)$ \\
\hline \multicolumn{4}{|c|}{ ORDER - HYMENOPTERA } \\
\hline Apis (Megapis) dorsata & 20.71 & Apis mellifera & $17 \cdot 57$ \\
\hline Apis cerana indica & 8.45 & Xylocopa latipes & 6.50 \\
\hline \multicolumn{4}{|l|}{ ORDER DIPTERA } \\
\hline Sarcophaga sp. & 5.08 & Orthellia viridis & 4.11 \\
\hline Hydrotaea diabolus & 4.41 & Chrysomya megacephala & 6.25 \\
\hline Lucilla Sericata & 2.76 & Musca indica & 5.08 \\
\hline Parasyrphus sp. & 5.76 & Eristalis sp. & 6.18 \\
\hline \multicolumn{4}{|c|}{ ORDER- LEPIDOPTERA } \\
\hline Euploea core & 1.34 & Danaus plexippus & 1.27 \\
\hline Papilio demoleus & 3.81 & & \\
\hline
\end{tabular}

Foraging efficiency of A.dorsata and A.mellifera on S.indicum flower: foraging efficiency can be determined by the analysis of VR (VR) and Handling Time (HT). The average VR for A.dorsata and A.mellifera were 4.04 \pm 0.32 flowers/minute and $3.7 \pm 0.32$ flowers/minute respectively. Moreover the average rate of flower Handling Time for A.dorsata and A.mellifera were 12.17 \pm 0.76 seconds/flower and 12.04 \pm 0.74 seconds/flower respectively.

A.dorsata and A.mellifera both showed the highest VR in the time interval of 8 am to 10 am in all the studied period (Fig.-3). Furthermore, A.dorsata and A.mellifera both spent maximum time on flower in the time frame of $8 \mathrm{am}$ to $10 \mathrm{am}$ (Fig.-4). There was no signif icant year wise variation occur in the VR and Handling Time among the different time frames of these two honey bees (Table-3). 


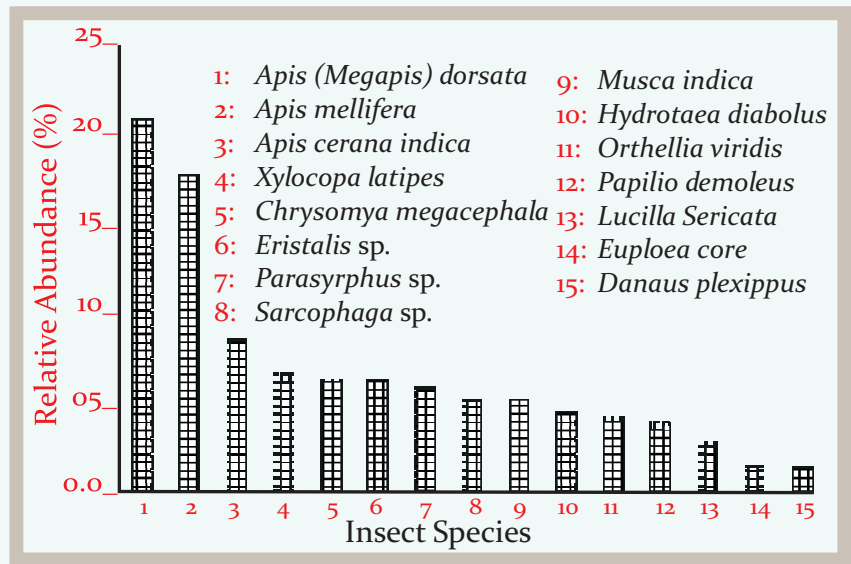

Figure-1: Rank plot of flower visitor species relative abundance (\%)

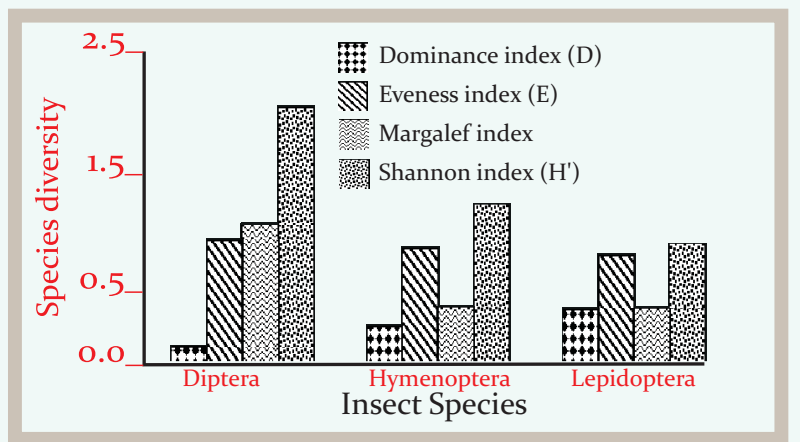

Figure-2: Bar graph of different ecological indices among different insect orders during the study period

Correlation analysis between the numbers of honeybees and flowers in each plant: an average number of $7.4 \pm 44$ bloomed flowers were present in each plant of S. indicum. On an average, $4.04 \pm 0.35$ individuals of A.dorsata and $3.74 \pm 0.29$ individuals of A.mellifera were reported from each plant of S.indicum during three minutes of a time duration for each monitoring period. The Linear regression data demonstrates that A.dorsata was included as a strong relationship with the blooming flower $\left(\mathrm{R}_{2}=0.3758\right.$, F-stat $=28.9$ on 1 and $48 \mathrm{df}, \mathrm{p}$ value $=$ 0.000002219), whereas, A.mellifera was showing very weak relationship with the blooming flower $\left(\mathrm{R}_{2}=0.1259\right.$, F-stat $=$ 6.913 on 1 and 48 df, pvalue $=0.01146)($ Fig. -5$)$.

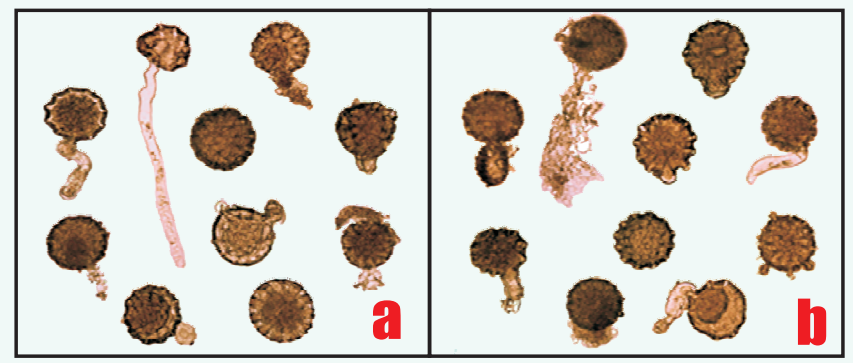

Plate-1: a) 77\% viable pollen collected from the anther lobe of the flower; b) $73 \%$ viable pollen collected from the body parts of the Apis (M) dorsata

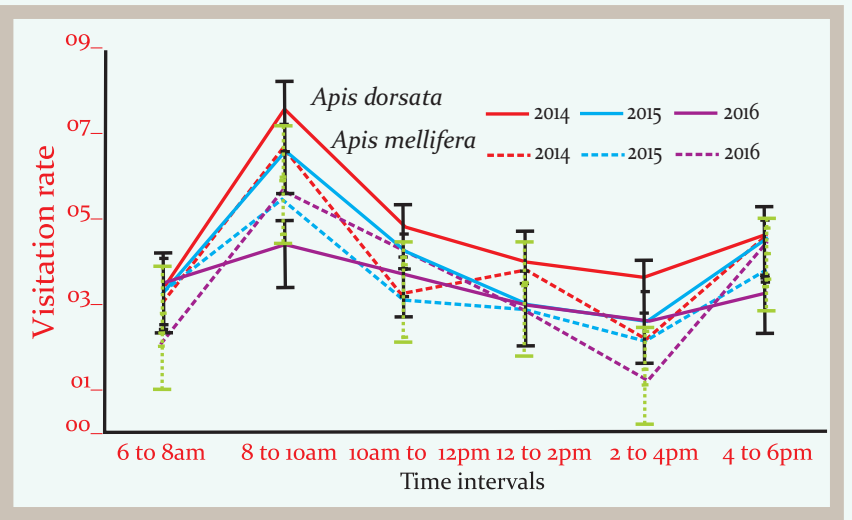

Figure-3: Year wise variations in VR of Apis (Megapis) dorsata (straight line)and Apis mellifera (dotted line)on the flower of Sesamum indicum invarious time frames.

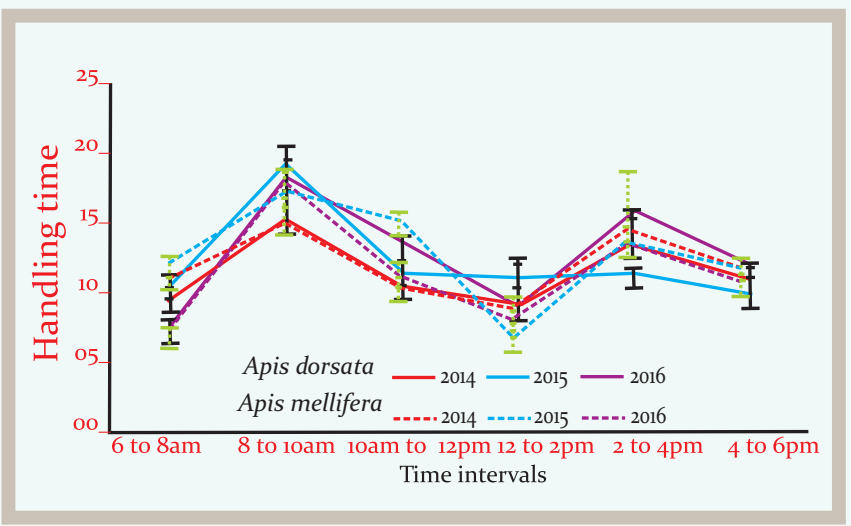

Figure-4:.Year wise variation of Handling Time of Apis (Megapis) dorsata (straight line)and Apis mellifera (dotted line)on the flower of Sesamum indicum in various time frames.

Table 3: One way Anova analysis among the VR and Handling Time of A.mellifera \& A.dorsata in different year wise variation among the six time intervals.

Factors $\quad$ Sumof Sq. df $\quad$ MS $\quad$ F-Value p-Value

\section{Apis mellifera: $V R$}

$\begin{array}{llll}\text { Between Groups } & 1.01333 & 2 & 0.5066670 .2389\end{array} \geq 0.7904$

Within Groups $\quad 31.8067 \quad 15 \quad 2.12044$

$\begin{array}{llll}\text { Total } & 32.82 & 17 & 0.7887\end{array}$

Apis mellifera: Handling Time

$\begin{array}{llllll}\text { Between Groups } & 5.24948 & 2 & 2.62474 & 0.2389 & \geq 0.7905\end{array}$

Within Groups $\quad 164.831 \quad 15 \quad 10.9887$

$\begin{array}{llll}\text { Total } & 170.08 & 17 & 0.786\end{array}$

Apis dorsata: VR

$\begin{array}{llllll}\text { Between Groups } & 4.68778 & 2 & 2.34389 & 1.452 & \geq 0.2652\end{array}$

Within Groups $\quad 24.215 \quad 15 \quad 1.61433$

$\begin{array}{llll}\text { Total } & 28.9028 & 17 & 0.2673\end{array}$

Apis dorsata:Handling Time

Within Groups $\quad 175.267 \quad 15 \quad 11.6845$

$\begin{array}{llll}\text { Total } & 179.509 & 17 & 0.8375\end{array}$

Pollination efficiency index and pollen germinability test:pollination efficiency has been analyzed to determine the efficiency of a pollen carrier regarding pollen carrying 
capacity. As A.dorsata and A.mellifera both were observed to carry pollen from this plant and both were efficient and abundant flower visitor of this plant, pollination efficiency was studied with a process developed by Vithanage (1990) for these two insects. Though A.mellifera was with higher flower and insect per hour ratio, A.dorsata was carrying a higher number of Sesamum pollen than A.mellifera. The pollination efficiency index also demonstrates that $A$. dorsata was more efficient than A.mellifera as a pollen carrier (Table-4). As A.dorsata showed more eff iciency with respect to pollen carrying activity, for effective pollination to happen. Therefore pollen germinability test was done in A.dorsata. This honey bee was carrying $73 \%$ of viable pollen of this plant whereas pollen collected from flower anther lobe included with $77 \%$ viable pollen (Plate-1).

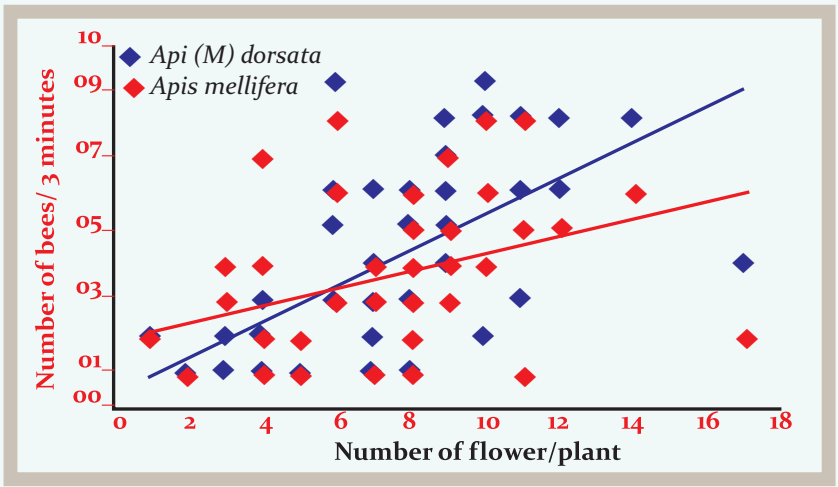

Figure-4: Linear regression relationship analysis between the number of bees and the bloomed flowers of Sesamum indicum plant. Apis (Megapis) dorsata (blue line), Apis mellifera (red line)

Table 4 Pollination Efficiency Index

\begin{tabular}{lllll}
\hline Insect Species & $\begin{array}{l}\text { Sesamum } \\
\text { Pollen }\end{array}$ & $\begin{array}{l}\text { Foreign } \\
\text { Pollen }\end{array}$ & $\begin{array}{l}\text { Flower: Insect } \\
\text { Ratio Per Hour } \\
\text { (F:I) }\end{array}$ & $\begin{array}{l}\text { Pollination } \\
\text { Efficiency } \\
\text { Index* }\end{array}$ \\
\hline Apis (M) dorsata & 838 & 47 & $150: 33$ & 3809 \\
Apis mellifera & 672 & 18 & $150: 41$ & 2458 \\
\hline
\end{tabular}

* Calculated using procedures developed by Vithanage (1990).

\section{Discussion:}

The study of seed yield among the self and cross-pollinated plants showed that, fruit length (length of the capsule) and plantlets size were not significantly varied in those two cases. Open pollination system included a significantly higher range of size regarding fruit diameter, seed length and seed width than close pollination system. Hence, it can be clearly determined from the above data of seed yield that the cross-pollinated plant showed more yield as compared to a self-pollinated plant.

Insect flower visitors can be predicted as a true source for cross-pollination in this plant. Related to the flower foragers of S.indicum, three insect orders viz., Diptera, Hymenoptera, and Lepidoptera were reported to be the most common for the cross-pollination. Among these three orders, order Diptera had the highest species diversity and richness followed by insects from order Hymenoptera and Lepidoptera. But the most abundant flower visitors were from the order Hymenoptera. Among the Dipteran insects, Chrysomya megacephala from family Calliphoridae was included with the highest abundance followed by Eristalis sp. from family Syrphidae. The insects of these two Dipteran family were reported to be as good flower visitors for this plant (Kamel et al., 2014). Again among order Hymenoptera, A.dorsata and A.mellifera were reported to be the most abundant species and had been observed to collect both pollen and nectar from the plant. However, the three insect species viz., Euploea core, Danaus plexippus, and Papilio demoleus from order Lepidoptera were found to collect the flower nectar only. Since their richness and abundance was much less compared to other insect orders so they can be considered as flower visitors for Sesamum and not playing a much active role in pollination.

The anthesis occurs early in the morning ( 6 am till 8:30 am) and stigma became receptive almost very close to that time (9 am till 10:30 am) and senescence occurs after six to twelve hours. Though it varies and depends on different environmental condition (Andrade et al., 2014). In the case of both the honey bee species, VR showed an increasing trend up to $12 \mathrm{pm}$ and after $12 \mathrm{pm}$ it showed a decreasing phenomenon. Thus, in the timeframe of $8 \mathrm{am}$ to $10 \mathrm{am}$ both the bees showed highest VR. Therefore the time of stigma receptivity in relation to pollen transfer was overlapping with the increasing VR for both the honey bee species which might increase the probability of pollen transfer and successful pollination in this plant. In the year wise variation study, there was no significant variation occurs in the VR and HT of both species. Therefore it easily depicted that the VR and HT for both of the honey bee species were following the same trend in relation to flowering phenomena. Hence it can be concluded that A.dorsata and A.mellifera both are playing an important role in pollination of S.indicum. Again, among these two honeybees, average VR and Flower HT were higher in A.dorsata than the other one. So, it can be concluded that A.dorsata was more efficient regarding VR and Flower HT than A.mellifera. Average numbers of individuals for A.dorsata were higher than average number of A.mellifera during the morning to evening study period. This phenomenon might be due to a more wild character of A.dorsata than other Hymenopteran insects, therefore A.dorsata could have visited much more abundantly. Furthermore, since there were no nearby apiculture practices done, the more cultivable and docile species of A.mellifera was found to be less abundant. An upward trend from the morning on both cases showed the highest prominent peak on 11 am but after that the number of individuals showed downward trend. Again a peak was shown for both A.dorsata and A.mellifera individual numbers at $5 \mathrm{pm}$. It was also supported by Dahat et al. 
(2017), who observed A.dorsata be most active during 11 am to $12 \mathrm{pm}$. Hence, from the present study it can be highlighted that though the VR and HT for both the honey bees was in the peak during the time frame of 8 to 10 am but the number of individuals was in peak at 11 am (Plate-1). Flower VR and HT both are important for determining the efficiency of the pollinators. VR is defined with the mobility of the pollinators and HT is def ined with the total time of foraging. This HT depends on the reward of the flower, finding the corolla, nectar extraction technique, proboscis length and in some cases flower colour (Merrabai, 2012; Herrera, 1989; Sanderson et al., 2006). The nectar extraction technique of bees are lapping with hairy glosse (Herrera, 1989) In the present study both the species are honeybees and therefore the HT pattern suggested the same trend for both the species. Proboscis length has an effect on HT time of different species (Herrera, 1989; Merrabai, 2012). Therefore may be due to longer proboscis length A.dorsata showed more HT than A.mellifera. In relation with flower blooming, both the honey bees species showed positive correlation. But, A.dorsata showed a strong relation with the bloomed flowers compared to A.mellifera. Regarding pollination index study, A.dorsata was carrying a sufficient number of viable pollen that further showed that the pollination efficiency was again high in A.dorsata.

Conclusively, the quantitative and qualitative present study with respect to seed yield demonstrates that S.indicum is more efficient in cross-pollination system. Considering the parameter such as VR, Flower HT, pollination eff iciency it was established that $A$.dorsata and A.mellifera both are an efficient visitor and pollen carrier for this plant but A.dorsata is more efficient as a pollinator of S.indicum plant. Therefore for enriching the seed yield of this plant the conservation of honey bee species is recommended.

\section{Acknowledgements:}

KB is indebted to the Dept. of Sci. \& Tech., W.B.,Govt. of India (DST, W.B.) for the financial support (Ref. No. 865/ST/P/S\&T/1G1/2015). BB is supported by grant from Rajiv Gandhi National Fellowship (2015-17-SC-WES-3634). UC is supported by grant from Swami Vivekananda Merit-cum-means scholarship. Authors are also thankful to PRG, University of Kalyani, 201718 for their partial financial support.

\section{References:}

Ali, A.I., Kairu, E.W., Abubakar, Z.M. \& Mchenga, S.S. (2016): Pollination and reproduction relationship of four mangroves species in Zanzibar, Tanzania. L. Global Biosci., 5(1):35723584 .

Andrade, P.B.de, Freitas, B.M., Rocha, E.de.M., Lima, J.A.de. \& Rufino, L.L. (2014): Floral Biology and pollination requirements of sesame (Sesamum indicum L.) Acta Scientiarum, 36(1):93-99.

Bhowmik, B. \& Bhadra, K. (2015): Insect pollinators and their role on the crop yield and quality of Sunflower (Helianthus annuus, PAC-361) from West Bengla, India. Int. J. Curr. Sci., 18(E):76-87.

Desai, B.B. (2004): Seeds handbook: biology, production, processing, and storage. Pub. by: Marcel Dekker, New York. $787 \mathrm{p}$.

Dahat, A.S., Tidke, J.A. \& Kale, P.J. (2017): Insect pollination, fruit set and seed yield in Sesamum indicum L. (Pedaliaceae). Int.J. Appl.Res., 3(3S)(F);166-171.

Damodaran T. \& Hegde DM. (2005): Oilseeds Situation: A Statistical Compendium Directorate Oilseeds Research. Pub. by: Indian Council of Agricultural Research, Hyderabad, India. 68 p.

Hammer Ø, Harper, D.A.T. \& Ryan, P.D. (2001): PAST: Paleontological statistics software package for education and data analysis. Palaeontologia Electronica, 4(1): 9pp.

Herrera, C.M. (1989): Pollinator abundance, morphology, and flower VR: Analysis of the "quantity" component in a plantpollinator system. Oecologia, 8o(2):241- 248.

Iqbal, A., Akhtar, R., Begum, T. \& Dasgupta, T. (2016): Genetic estimates and diversity study in Sesame (Sesamum indicum L.).J.Agri. Veterin. Sci., 9(8):1-5.

Irshad, M. \& Stephen, E. (2014): Review: Pollination, Pollinated and Pollinators interaction in Pakistan. J. Biores. Manage., 1(1):19-25.

Jonathan JK \& Kulkarni PP. (1986): Manual: Collection, preservation and identification of insects and mites of economic importance (Ed.: Tikader B.K.). Pub. by: Zoological Survey of India. $322 \mathrm{p}$.

Kamel, M., Blal, A.H., Mahfouz, H.M. \& Said, M. (2014): The most common insect pollinator species on sesame crop (Sesamum indicum L.) in Ismailia Governorate, Egypt. Arthropods, 2(2):66-74.

Klein, A-M., Vaissière, B.E., Cane, J.H. \& Tscharntke, T. (2007): Importance of pollinators in changing landscapes for world crops. Pro. Roy. Soc., - B. 274(1608):303-313.

Mahmoud, M.F. (2012): Insects associated with Sesame (Sesamum indicum L.) and the impact of insect pollinators on crop production. Pestic. Phytomed. (Belgrade), 27(2):117-129.

Meerabai G.(2012): Vistation rate, effectiveness and efficiency of pollinators to Cadaba fruiticosa (Linn.) Druce. Bioscan. $7(3): 483-485$.

Price, P.W. (1975): Insect Ecology. Pub. by: John Wiley and Sons, New York, USA. 514p.

Raikwar, R.S. \& Srivastva, P. (2013): Productivity enhancement of sesame (Sesamum indicum L.) through improved production technologies. Af.J.Agri. Res., 8(47):6073-6078.

Saini, H., Kaur, G. \& Banga, S. (2012): Application of GGE biplot analyses for characterizing diverse sesame (Sesamum indicum) germplasm for yield and yield-contributing traits. Indian J. Agri. Sci., 82(9):759-767.

Sanderson, E.C., Orozco, B.S., Hill, P.S.M. \& Wells, H. (2006): Honeybee (Apis mellifera ligustica) Response to differences in handling time, rewards and flower colours. Ethology. $112(10): 937-946$.

Vithanage, V. (1990): The role of European honeybee (Apis mellifera L.) in avocado pollination. J. Horti. Sci., 65(1):s81-89. 